\title{
Diagnosis and management of cerebral venous thrombosis
}

\author{
Authors: Roya Behrouzi ${ }^{A}$ and Martin Punter ${ }^{B}$
}

Cerebral venous thrombosis (CVT) is rare and accounts for $0.5 \%$ of all strokes. Its clinical presentation is variable and diagnosis requires a high index of clinical suspicion in conjunction with neuroradiological diagnostic support. Treatment options are limited and are mostly based on consensus. Therefore, familiarity with international guidelines is important. Outcome is often good and most patients make a full recovery, although a small proportion suffers death or disability. Here, we describe the clinical features, risk factors, acute imaging features, management and complications of CVT.

\section{Introduction}

Stroke is one of the leading causes of death and long-term disability and is usually caused by arterial occlusion or haemorrhage. Cerebral venous thrombosis (CVT) is rare and accounts for $0.5 \%$ of all strokes. ${ }^{1}$ Presentation can also be with non-stroke syndromes and overall CVT has an incidence of 0.22 $1.32 / 100,000 /$ year. $^{2}$ In contrast to arterial stroke, it occurs more frequently in young adults and children. ${ }^{2,3}$ It is three times more common in females than in males, ${ }^{2}$ although this sex difference is minimal in the over-60 age group.,

The principle pathology of CVT is thrombosis of cerebral veins and the commonest site of origin is believed to be the junction of cerebral veins and larger sinuses. ${ }^{5}$ The superficial cerebral venous system includes the cortical veins, the superior (Trollard) and inferior (Labbe) anastomotic veins and the superficial middle cerebral vein. These drain into the superior sagittal sinus (cortical and Trollard), the transverse sinus (Labbe) and cavernous sinus, respectively. The basal vein of Rosenthal, vein of Galen and transcerebral venous system drain the deep structures of the brain and form the inferior sagittal sinus and straight sinus.

Once a thrombus is formed in the cerebral or cortical veins, its extension can occlude large draining venous sinuses. This creates physiological back pressure in the venous system, leading to cerebral oedema and, in some cases, infarction and haemorrhage. Dural sinus thrombosis is also thought to reduce cerebrospinal

Authors: A consultant neurologist and stroke physician, University Hospital of South Manchester NHS Foundation Trust, Manchester, UK; ${ }^{\mathrm{B}}$ academic foundation doctor, Manchester University NHS Foundation Trust, Behaviour and Mental Health, Manchester, UK fluid absorption and thereby elevate intracranial pressure (ICP). ${ }^{6}$ Historically, CVT was diagnosed at post-mortem, but, with access to modern neuroimaging techniques and increased awareness among clinicians, ante-mortem diagnosis is now usual. Management of CVT is aimed at early identification and prevention of thrombus extension and complications. It has been observed in the UK that there is some variation in management of $\mathrm{CVT}^{7}$ and it is important to be aware of recent guidelines. ${ }^{4,8-10}$ Prognosis is usually good, with up to $80 \%$ of patients making a complete recovery. ${ }^{11}$ However, a significant minority $(-13 \%)$ have a poor outcome in terms of death or severe disability. ${ }^{11,12}$

\section{Clinical features of CVT}

The clinical presentation of CVT is variable and falls broadly into three categories: symptoms and signs of raised intracranial pressure (ICP), a focal brain lesion, or both a focal lesion and raised ICP. Mode of onset is also variable and up to $40 \%$ of patients present acutely with a stroke-like syndrome within $48 \mathrm{~h}$ of symptom onset. More than $50 \%$ present within 1 month of

\section{Key points}

CVT is rare and potentially disabling, but for most patients who survive, prognosis is good

Prompt diagnosis and treatment could be key to good outcomes and preventing complications

Working closely with clinical and radiological expertise benefits patient care

Anticoagulation is a cornerstone of treatment, even in the presence of haemorrhage

Understanding roles of multiple risk factors is important to help with treatment decisions and will help in understanding the disease in the future

KEYWORDS: cerebral venous thrombosis, cerebral venous sinus thrombosis, anticoagulation, stroke, imaging, cerebral venography and heparin 
symptom onset and a small proportion ( $7 \%$ ) present with chronic symptoms of greater than 1 month's duration. ${ }^{11}$ Non-specific symptoms are present in the majority and, for this reason, patients can present to a variety of services, including acute medicine, stroke, acute neurology and neurosurgery.

Presenting clinical features can depend on the location of the thrombus and the extent of raised ICP, including whether it is related to venous pressure alone or extensive parenchymal damage (Table 1). Headache is the most common symptom and is present in $\sim 90 \%$ of cases; in $25 \%$ of patients, it is the only symptom reported. ${ }^{4}$ Headache can be a feature of any site of cerebral venous occlusion, but is most prominent with larger sinus thromboses, such as sagittal sinus or straight sinus thromboses.
This headache syndrome can range from a common migraine to clear features of raised ICP, ${ }^{13}$ where papilloedema might also be visualised with fundoscopy. Given a lower incidence of headache in arterial stroke (25-30\%), ${ }^{14}$ the presence of severe headache in the context of stroke-like symptoms can raise suspicion of CVT. As well as headache, CVT can present with other craniofacial pain. Notably, pain in the ear or mastoid region with or without discharge can be suggestive of transverse sinus thrombosis secondary to mastoiditis. Seizures are also a more common presenting feature in CVT compared with arterial stroke ( $40 \%$ vs $6 \%) .{ }^{11,15}$ Focal neurological symptoms and signs are common, such as motor weakness (present in up to $40 \%$ of patients), visual field loss, sensory symptoms, inattention or neglect. ${ }^{11}$ These features

Table 1. Signs and symptoms of cerebral venous thrombosis (CVT) and location of probable lesion

\begin{tabular}{|c|c|c|}
\hline \multicolumn{2}{|l|}{ Signs and symptoms } & Probable lesion \\
\hline \multirow[t]{4}{*}{ Headache } & Migraine & Any venous occlusion/focal lesion \\
\hline & Raised ICPa & Large venous or sinus occlusion/large mass lesion \\
\hline & Thunderclap & Any venous occlusion/subarachnoid haemorrhage \\
\hline & Ear/mastoid pain & Transverse sinus with/without infection \\
\hline \multirow[t]{12}{*}{ Focal neurological deficits } & Hemiparesis & Infarction/haemorrhage/venous oedema \\
\hline & Cranial nerve palsy & \\
\hline & III, IV & Cavernous sinus \\
\hline & V & Cavernous sinus/superior petrosal sinus \\
\hline & VI & Cavernous sinus/inferior petrosal sinuses/raised ICP \\
\hline & VII & Transverse/sigmoid sinus \\
\hline & VIII & Transverse/sigmoid sinus/raised ICP \\
\hline & IX, X, XI & Posterior cavernous sinus/internal jugular vein/deep venous system \\
\hline & Aphasia & Focal infarction/haemorrhage/superficial or deep venous system \\
\hline & Sensory disturbance & Focal infarction/haemorrhage/superficial or deep venous system \\
\hline & Inattention/neglect & Focal infarction/haemorrhage/superficial venous system \\
\hline & Ataxia & Cerebellar veins/raised ICP \\
\hline \multirow[t]{2}{*}{ Seizures } & Focal & Focal infarction/haemorrhage \\
\hline & Generalised & Focal infarction/haemorrhage/severely raised ICP \\
\hline \multirow[t]{4}{*}{ Visual disturbance } & Reduced acuity & Raised ICP \\
\hline & Reduced/altered visual field & Raised ICP/Posterior infarction/haemorrhage/raised ICP (false localising sign) \\
\hline & Diplopia & Cavernous sinus/petrosal sinus/raised ICP \\
\hline & Papilloedema & Raised ICP \\
\hline \multirow[t]{2}{*}{ Meningism } & Neck pain/stiffness & Suggests infectious or inflammatory aetiology \\
\hline & Photophobia & \\
\hline \multirow[t]{3}{*}{ Reduced consciousness } & Drowsiness & Deep venous system/straight sinus/raised ICP/non-convulsive status epilepticus \\
\hline & Stupor & \\
\hline & Coma & \\
\hline \multirow[t]{4}{*}{ Cognitive impairment } & Encephalopathy & Deep venous system/temporal-parietal lesion (vein of Labbe)/seizures \\
\hline & Disorientation & \\
\hline & Reduced concentration & \\
\hline & Amnesia & \\
\hline
\end{tabular}

${ }^{a}$ Raised intracranial pressure (ICP) can result from a combination of a large venous/sinus occlusion or from large infarction/haemorrhage. 


\begin{tabular}{|c|c|}
\hline \multirow[t]{2}{*}{ Thrombophilias } & Genetic - eg Factor V Leiden \\
\hline & Acquired - eg antiphospholipid syndrome \\
\hline \multirow[t]{3}{*}{ Infection } & Intracranial \\
\hline & Regional eg ear, nose, throat, head, neck \\
\hline & Systemic \\
\hline \multirow[t]{4}{*}{ Trauma } & Head injury \\
\hline & Cranial surgery \\
\hline & Lumbar puncture \\
\hline & Endovascular intervention \\
\hline \multirow[t]{2}{*}{ Reproductive } & Pregnancy \\
\hline & Puerperium \\
\hline \multirow[t]{2}{*}{ Malignancy } & Intracranial \\
\hline & Extracranial \\
\hline \multirow[t]{3}{*}{ Medications } & Oral contraceptives \\
\hline & Steroids \\
\hline & $\begin{array}{l}\text { Anti-neoplastic drugs (particularly } \\
\text { L-asparaginase) }\end{array}$ \\
\hline \multirow[t]{4}{*}{ Inflammatory } & Vasculitis eg Behçet's disease \\
\hline & Systemic lupus erythematosus \\
\hline & Inflammatory bowel disease \\
\hline & Sarcoidosis \\
\hline \multirow[t]{2}{*}{ Haematological } & Iron deficiency anaemia \\
\hline & Polycythaemia \\
\hline Endocrine & Hyperthyroidism \\
\hline \multirow[t]{2}{*}{ Systemic } & Dehydration \\
\hline & Sepsis \\
\hline \multirow{3}{*}{$\begin{array}{l}\text { Intracranial } \\
\text { abnormalities }\end{array}$} & Dural fistulae \\
\hline & Venous anomalies \\
\hline & Arteriovenous malformations \\
\hline
\end{tabular}

are suggestive of a focal lesion, which can range from cortical vein occlusion with consequent oedema, to larger vessel occlusion with large-volume infarction or haemorrhage. A patient presenting with rapid cognitive deterioration leading to drowsiness or coma is suggestive of deep venous occlusion with infarction of the thalamus.

\section{Risk factors for CVT}

Cerebral venous thrombosis can be provoked or unprovoked and numerous risk factors can coexist in individual patients. ${ }^{4,8,13}$ In patients who present with appropriate clinical features, the risk factors shown in Table 2 should be considered. Up to $90 \%$ of patients with CVT have at least one risk factor for venous thromboembolism (VTE), and thrombophilias (genetic or acquired) are detected in more than $30 \%$ of patients. ${ }^{11}$ Female-specific risk factors are more important in younger age groups (ie oestrogencontaining contraceptives, pregnancy and puerperium) and malignancy is more common in older age group. ${ }^{4,8}$ The presence of any of these risk factors should raise suspicion of CVT and their identification can help inform long-term treatment choices.

\section{Radiological diagnosis of CVT}

Radiological investigation is important to the diagnosis of CVT and working with radiologists to identify the most appropriate imaging techniques is crucial. In most acute hospitals, computerised tomography (CT) of the brain is widely available and is the most common initial imaging used in acute stroke presentations. Subacute ischaemia and acute haemorrhage (parenchymal or subarachnoid) are readily identified by CT imaging (Fig 1a,b). There are certain characteristics of parenchymal lesions that are suggestive of CVT, including bilateral or parasagittal lesions (Fig 1c), lesions crossing arterial territories, and juxtacortical lesions. ${ }^{17}$ In some cases, thrombus in cerebral venous sinuses can be seen as hyperdense on plain CT (Fig 1d). ${ }^{18}$ CT has the advantage that a CT venography (CT-V) protocol can be easily added and reliably demonstrates occlusive disease in the major cerebral veins and sinuses (Fig 1e). ${ }^{19,20}$

Magnetic resonance imaging (MRI) and magnetic resonance venography (MR-V) are also sensitive tools for identifying CVT. ${ }^{4,14}$ These have the advantage of being more sensitive for diagnosing alternative pathologies and more-subtle brain lesions, as well as reducing exposure to ionising radiation. However, MR-V is

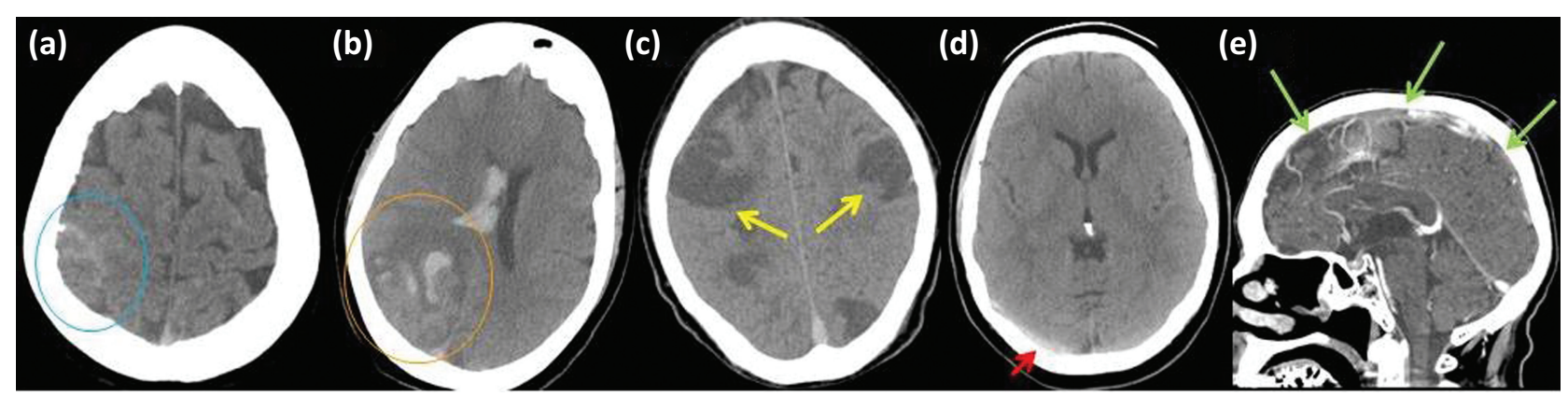

Fig 1. Non-contrast computerised tomography (CT) scans of brain. Demonstrating (a) hyperdensity over the right parietal cortex signifying subarachnoid haemorrhage (blue circle); (b) right occipital lobe haemorrhagic infarction with additional intraventricular haemorrhage (orange circle); (c) extensive and bilateral cerebral infarction (yellow arrows); and (d) hyperdensity in right transverse sinus demonstrating thrombosis (red arrow). (e) CT venogram demonstrating multiple areas of failed opacification of the superior sagittal sinus, representing thrombotic occlusion (green arrows) 
more susceptible to motion and low-flow image artefacts, and appearances can vary depending on the age of the thrombus. ${ }^{19}$ In chronic cases, gradient echo (GRE) or susceptibility-weighted imaging (SWI) can be useful to demonstrate low signal in thrombosed sinuses. ${ }^{4}$ Occasionally, catheter angiography is useful when there is doubt about the anatomy, but the requirement of highly skilled operators limits its access to neuroscience centres.

\section{Management of CVT}

Management of CVT is focused on timely diagnosis and treatment. Treatment is predominantly anticoagulation to prevent propagation of the thrombus and reduce the likelihood of complications, such as pulmonary embolus. Factors predictive of poor prognosis include large parenchymal lesions, age greater than 37 years, Glasgow Coma Score (GCS) less than 9/15, seizures, posterior fossa lesions, intracranial haemorrhages or any malignancy; ${ }^{11,12}$ these patients are more likely to deteriorate and need management in acute settings.

Both the American Heart Association and American Stroke Association (AHA/ASA) and the European Federation of Neurological Societies (EFNS) guidelines recommend that patients should be anticoagulated even in the presence of haemorrhage. ${ }^{21}$ Evidence for this is limited to two small randomised controlled trials (RCTs) of unfractionated heparin (UFH) ${ }^{22}$ and low-molecularweight heparin $(\mathrm{LMWH}) .{ }^{23}$ Both RCTs showed better clinical outcomes and reduced mortality rates in patients receiving anticoagulation compared with controls, without increased incidence of intracranial haemorrhage. ${ }^{22,23}$ A meta-analysis of both RCTs showed a $13 \%$ absolute reduction in mortality or dependency in anticoagulated patients, although this was not statistically significant. ${ }^{24}$ There is still debate around the most appropriate method of anticoagulation. In systemic VTE, studies suggest that $\mathrm{LMWH}$ is superior to UFH at prevention and reducing thrombus size, ${ }^{25}$ but it is unclear whether this can be applied to CVT. However, a recent single-centre RCT demonstrated a significantly lower mortality rate in patients receiving LMWH compared with UFH. ${ }^{26}$ Currently, the recommendation is immediate commencement of therapeutic LMWH or UFH. In addition to anticoagulation, underlying aetiological factors should be investigated and managed. Immediately reversible risk factors should be addressed, such as stopping prothrombotic drugs, rehydration, and antibiotics (Table 2). It might be appropriate to screen for prothrombotic and/or genetic factors, but not in the acute phase, and it is usually helpful to seek guidance from a haematologist. If an infective or inflammatory cause is suspected, particularly in the head and neck, lumbar puncture (LP) should be considered if there is no contraindication, such as a mass lesion (large infarction and/or haemorrhage). ${ }^{4}$ This should ideally be performed immediately before anticoagulation.

In some cases, patients might not respond to treatment with continued deterioration, and $9-13 \%$ of patients with CVT have a poor outcome despite anticoagulation. ${ }^{4}$ Transtentorial herniation because of raised ICP is the most common cause of death. ${ }^{12}$ Most patients will have symptoms and signs of raised ICP and it is vital to carry out fundoscopy and monitor for progressive visual loss. ${ }^{4}$ Treatment with acetazolamide, although of limited evidence base, can be considered in raised ICP without immediate risk of uncal herniation. ${ }^{4,8}$ Lumbar puncture can rarely be performed during the emergent phase after anticoagulation. However, performing an
LP necessitates cessation of anticoagulation and, although time off anticoagulation can be mitigated by using UFH, there remains a risk of further thrombosis. Therefore, LP should be reserved for suspected severe raised ICP, including with threat to vision, when other definitive neurosurgical measures might also need to be considered.

If anticoagulation is contraindicated, or in cases of severe CVT not responding to anticoagulants, endovascular thrombolysis or mechanical thrombectomy might be an option, ${ }^{27,28}$ although evidence to support this approach is currently lacking. Steroids are not recommended and are linked to a poorer prognosis in CVT, even with the presence of parenchymal lesions, unless indicated by an underlying condition, such as meningitis or malignancy. ${ }^{29}$ Antiepileptic drugs should not be given routinely as prophylaxis but should be initiated quickly if a seizure occurs. ${ }^{4}$ Patients with rapid neurological deterioration because of impending herniation can benefit from decompression with craniectomy. ${ }^{30,31}$

Following the immediate management of CVT, long-term vitamin $\mathrm{K}$ antagonists, such as warfarin, with a target international normalised ratio (INR) of 2-3 should be used. The duration of anticoagulation depends on aetiology. The AHA/ASA guidelines recommend anticoagulation for 3-6 months in provoked CVT, 6-12 months in unprovoked CVT and potentially lifelong in recurrent CVT, VTE following CVT, or CVT associated with severe thrombophilias. ${ }^{4}$ More recently, the American College of Chest Physicians (ACCP) guideline ${ }^{32}$ suggests that, for provoked VTE, anticoagulation should continue for 3 months, and for unprovoked should be reviewed after 3 months and thereafter annually for bleeding risk. It is not clear whether this can be applied to CVT, which, to some extent, has a different risk factor profile. There appears to be no role for deciding the length of anticoagulation based on recanalisation because this only occurs during the first few months after CVT, and no correlation has been found between recanalisation and clinical outcome. ${ }^{30}$ Finally, it is worth mentioning direct oral anticoagulants (DOACs). Studies have shown that DOACs are no less effective than warfarin in both the treatment of VTE and prevention of recurrence. ${ }^{34}$ However, for CVT, there are only a few observational studies available, with one of the largest involving just 15 patients. ${ }^{35}$ In the absence of clear evidence, DOACs remain a potential treatment option in patients for whom warfarin is not suitable, but would not be recommended as a first-line therapy.

\section{Conclusion}

Cerebral venous thrombosis is a rare, potentially life-threatening disease presenting in a variety of ways and to a variety of services. Diagnosis involves collaboration between clinical and radiological teams with a high index of clinical suspicion. Heparin is the mainstay of acute treatment for patients found to have CVT and duration of anticoagulation beyond the acute phase depends on the aetiology and association of modifiable and unmodifiable risk factors. An awareness of potential complications will help in their anticipation and management. It is also important to be aware of available guidelines on the investigation and treatment of the disease, because there is limited evidence to support particular strategies.

\section{Declaration of interests}

The authors declare no competing interests. 


\section{References}

1 Bousser M-G, Ferro JM. Cerebral venous thrombosis: an update. Lancet Neurol 2007;6:162-70.

2 Coutinho JM, Zuurbier SM, Aramideh M, Stam J. The incidence of cerebral venous thrombosis: a cross-sectional study. Stroke 2012:43:3375-7.

3 Ferro JM, Canhao P. Cerebral venous sinus thrombosis: update on diagnosis and management. Curr Cardiol Rep 2014;16:523.

4 Saposnik G, Barinagarrementeria F, Brown RD et al. Diagnosis and management of cerebral venous thrombosis: a statement for healthcare professionals from the American Heart Association/ American Stroke Association. Stroke 2011;42:1158-92.

5 Bousser M-G, Russell RWR. Cerebral venous thrombosis. London: Saunders, 1997.

6 Stam J. Thrombosis of the cerebral veins and sinuses. N Engl J Med 2005;352:1791-8.

7 Lavin T, Holland M, Punter M. Organisation of services and clinical practice in acute cerebral venous sinus thrombosis: a UK survey. J Neurol Neurosurg Psychiatr 2017;pii:jnnp-2017-316118

8 Einhaupl K, Stam J, Bousser M-G et al. EFNS guideline on the treatment of cerebral venous and sinus thrombosis in adult patients. Eur J Neurol 2010;17:1229-35.

9 Punter M, Kawafi K, Kellett M et al. North west guidelines for cerebral venous sinus thrombosis. NHS, 2016.

10 Ferro JM, Bousser M-G, Canhão P et al. European Stroke Organization guideline for the diagnosis and treatment of cerebral venous thrombosis - endorsed by the European Academy of Neurology. Eur Stroke J 2017;24:1203-13.

11 Ferro JM, Canhão P, Stam J, Bousser M-G, Barinagarrementeria F. Prognosis of cerebral vein and dural sinus thrombosis. Stroke 2004;35:664-70.

12 Canhão P, Ferro JM, Lindgren AG et al. Causes and predictors of death in cerebral venous thrombosis. Stroke 2005;36:1720-5.

13 Alberti A, Venti M, Biagini S. Headache and cerebral vein and sinus thrombosis. Front Neurol Neurosci 2008;23:89-95.

14 Tentschert S, Wimmer R, Greisenegger S, Lang W, Lalouschek W. Headache at stroke onset in 2196 patients with ischemic stroke or transient ischemic attack. Stroke 2005;36:e1-3.

15 Dávalos A, Cendra E, Genís D, López-Pousa S. The frequency, characteristics and prognosis of epileptic seizures at the onset of stroke. J Neurol Neurosurg Psychiatry 1988;51:1464.

16 Saadatnia M, Fatehi F, Basiri K, Mousavi SA, Mehr GK. Cerebral venous sinus thrombosis risk factors. Int J Stroke 2009;4:111-23.

17 Coutinho JM, van den Berg R, Zuurbier SM et al. Small juxtacortical hemorrhages in cerebral venous thrombosis. Ann Neurol 2014:75:908-16

18 Selim M, Caplan LR. Radiological diagnosis of cerebral venous thrombosis. Front Neurol Neurosci 2008:23:96-111.

19 Khandelwal N, Agarwal A, Kochhar R et al. Comparison of CT venography with MR venography in cerebral sinovenous thrombosis. Am J Roentgenol 2006;187:1637-43.

20 Casey SO, Alberico RA, Patel $\mathrm{M}$ et al. Cerebral CT venography. Radiology 1996;198:163-70.
21 Coutinho ], de Bruijn SF, Deveber G, Stam J. Anticoagulation for cerebral venous sinus thrombosis. Cochrane Database Syst Rev 2011;CD002005.

22 Einhäupl KM, Villringer A, Mehraein S et al. Heparin treatment in sinus venous thrombosis. Lancet 1991;338:597-600.

23 Bruijn SFTM de, Stam J. Randomized, placebo-controlled trial of anticoagulant treatment with low-molecular-weight heparin for cerebral sinus thrombosis. Stroke 1999;30:484-8.

24 Coutinho J, de Bruijn SF, Deveber G, Stam J. Anticoagulation for cerebral venous sinus thrombosis. Cochrane Database Syst Rev 2011;CD002005.

25 Robertson L, Jones LE. Fixed dose subcutaneous low molecular weight heparins versus adjusted dose unfractionated heparin for the initial treatment of venous thromboembolism. Cochrane Database Syst Rev 2017;CD001100.

26 Misra UK, Kalita J, Chandra S, Kumar B, Bansal V. Low molecular weight heparin versus unfractionated heparin in cerebral venous sinus thrombosis: a randomized controlled trial. Eur ] Neurol 2012;19:1030-6.

27 Canhão P, Falcão F, Ferro JM. Thrombolytics for cerebral sinus thrombosis: a systematic review. Cerebrovasc Dis 2003;15:159-66.

28 Stam J, Majoie CBLM, van Delden OM, van Lienden KP, Reekers JA. Endovascular thrombectomy and thrombolysis for severe cerebral sinus thrombosis. Stroke 2008:39:1487-90.

29 Canhão P, Cortesão A, Cabral M et al. Are steroids useful to treat cerebral venous thrombosis? Stroke 2008;39:105-10.

30 Aaron S, Alexander M, Moorthy RK et al. Decompressive craniectomy in cerebral venous thrombosis: a single centre experience. $]$ Neurol Neurosurg Psychiatry 2013;84:995-1000.

31 Crassard I, Bousser M-G, Canhao P et al. Decompressive surgery in cerebrovenous thrombosis (CVT). A systematic review of individual patient data. Cerebrovasc Dis 2010;29:286

32 Kearon C, Akl EA, Ornelas ] et al. Antithrombotic therapy for vte disease: chest guideline and expert panel report. Chest 2016;149:315-52

33 Agarwal A, Lowry P, Isaacson G. Natural history of sigmoid sinus thrombosis. Ann Otol Rhinol Laryngol 2003;112:191-4.

34 van Es N, M Coppens, Schulman S, Middeldorp S, Büller HR. Direct oral anticoagulants compared with vitamin $\mathrm{K}$ antagonists for acute venous thromboembolism: evidence from phase 3 trials. Blood 2014;124:1968-75.

35 Mendonça MD, Barbosa R, Cruz-e-Silva V, Calado S, Viana-Baptista $M$. Oral direct thrombin inhibitor as an alternative in the management of cerebral venous thrombosis: a series of 15 patients. Int J Stroke 2015;10:1115-8.

Address for correspondence: Dr Martin Punter, Greater Manchester Neurosciences Centre, Salford Royal NHS Foundation Trust, Stott Lane, Salford M6 8HD, UK. Email: martin.punter@manchester.ac.uk 